\title{
Organizational Politics And Workplace Deviance In Unionized Settings: Mediating Role Of Job Stress And Moderating Role Of Resilience
}

This article was published in the following Dove Press journal: Psychology Research and Behavior Management

\author{
Mohsin Bashir ${ }^{1}$ \\ Muhammad Abrar' \\ Muhammad Yousaf ${ }^{2}$ \\ Shahnawaz Saqib (ID) \\ Rizwan Shabbir' \\ 'Faculty of Economics and Management \\ Sciences, Lyallpur Business School, \\ Government College University, \\ Faisalabad, Pakistan; ${ }^{2}$ Rahim Yar Khan \\ Division, MEPCO, Punjab, Pakistan
}

Background: Politics and political behaviors are a vicious and bitter reality in an organization's life. Although under investigation for more than three decades, the literature lacks sufficient studies investigating culture-specific potential factors which have the potency to moderate the poisonous consequences of organizational politics. The aim of this study was to investigate the relationship of organizational politics and deviance in unionized settings with the moderating role of resilience in unionized employees in higher power distance culture.

Methods: A cross-sectional design was followed for data collection. The population of this study was low-ranked employees having union identity and working in the largest power distribution company of Pakistan. Stratified sampling was applied, and eight strata's were considered on the basis of geographical distribution, a total of 400 questionnaires were distributed among the employees of eight circles, fifty from each. Smart PLS.3.2.0 was used to analyze data through Structural Equation Modeling (SEM) under measurement and structural models.

Conclusion: From a theoretical perspective, this study confirmed that employees tend to show interpersonal deviance when they experience organizational politics, but organizational politics does not promote organizational deviance. Under stress, the individual also shows a slightly higher level of interpersonal deviance as compared to organizational deviance. However, the moderating role of resilience has not been proved in this study. Research limitations and future directions have also been discussed.

Keywords: organizational politics, interpersonal deviance, organizational deviance, job stress, resilience, lower-level employees

\section{Background Of The Study}

Organizational politics is under extensive investigation from the last three decades, ${ }^{1-7}$ but there is still a need to conduct culture-specific studies to explore the consequences of organizational politics ${ }^{8}$ because in collectivist culture individuals might have different exposures to stress generated through organizational politics. Asian societies are mostly collectivist in nature and orientation of culture in Pakistan is also collectivist, ${ }^{9}$ and individuals here may have different perceptions towards experiencing the stress. In high power distance, culture subordinates may feel a higher level of power gap due to the centralization of authority, and they might involve themselves in political activities within the organization to gain power. ${ }^{9}$ Although most of the literature claimed that politics is ubiquitous within organizations, but it needs more consideration, and empirical examination. ${ }^{10}$ Culture-specific potential factors have not been explored yet which have
Correspondence: Shahnawaz Saqib Lyallpur Business School, Faculty of Economics and Management Sciences, Government College University, Ist Floor, Jinnah Block, Lyallpur Business School, Government College University, New Campus, Jhang Road, Faisalabad, Pakistan

Tel +92300670450I

Email shahnawaz_saqib@yahoo.com 
the potency to moderate the impact of organizational politics. ${ }^{8}$ Thus literature still lacks sufficient studies which have investigated the relationship of organizational politics and behaviors ${ }^{11}$ in different cultural settings.

In organizations, politics is merely a reality of life; ${ }^{12}$ thus, the practice of political strategies in organizations is wellknown. Real-life experience, intuitions and circumstantial proof for years have maintained a general faith that behavior of organizations is habitually political in nature. It is the vicious and bitter reality politics and political behaviors in organizations are unavoidable behavior. Organizational politics now has become a substantial research interest area in the context of behaviors and perceptions. ${ }^{13}$ Earlier studies have verified the drastic consequences of organizational, political perception on organizational commitment ${ }^{14}$ engagement with work, job stress, ${ }^{12,15}$ job satisfaction, ${ }^{16}$ turnover intentions, ${ }^{12,17}$ and inno-

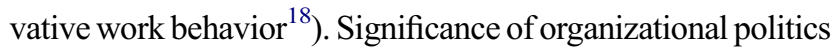
lies in its possible potential negative consequences on personal and work-related outcomes. Previous literature has laid down extensive evidence that politics in the organization raises the negative perception of fairness, moderate organizational commitment, and at the end of the day, necessitates turnover plans or turnover. ${ }^{19}$ Although the cost and prevalence of workplace deviance within organizations is high ${ }^{20}$ but very little has been explored up till now to document the dark relationship between politics and deviance in unionized public sector organizations. Hence the prevalence of deviant behaviors within organizational circuits is an economic threat for the wellbeing of employee and employer. $^{21}$

Organizational politics has been defined as socially influencing behaviors which are strategically designed to maximize self-interest or self-serving behavior. ${ }^{22}$ This definition carries a negative connotation but is consistent with the general view of employees; when asked to talk about workplace politics, employees typically describe it in negative terms. ${ }^{23}$ Prevalence of this negative perception among employees can be poisonous for both individuals and organizations.

In highly collectivist nations such as Pakistan ${ }^{9}$ individuals might have greater tendencies to develop their bond with unions. In Pakistan, Unions are now mainly found in public sector institutions which deal in public utilities like electricity, gas, telecommunication, airline and postal services. Unions in such public institutions have been found the main reason for the decline in performance ${ }^{24}$ because politics takes places at all levels within organizational circuits. $^{25}$ Unions have significant power to influence organizations. $^{26}$ Although the presence of Union's has been witnessed in both private and public sectors, but the public sector is more influenced by the presence of unions, ${ }^{24}$ and such institutes are more vulnerable to experience exploitation in the presence of organizational politics. ${ }^{27,28}$ Particularly in a developing nation such as Pakistan, which is highly power distance, Unions have received a rare amount of attention in public sector organizations. ${ }^{24}$ Due to such instances we have selected employees from largest public sector power Distribution Company (a public utility company) which looks after the affairs of electricity distribution with a working strength of 24,854 employees of various cadres, serving across the thirteen districts and 33.3 Million population approximately ("MEPCO | Multan Electric Power Company"). ${ }^{29}$ Another reason for selecting this public utility organization was the presence of strong unions in distribution companies. Moreover in unionized settings union members tend to express greater willingness to engage in politics $^{30}$ and thus, unions in democratic societies are relatively more apt to mobilize members toward contentious tactics, such as demonstrations ${ }^{31}$ which can lower organizational performance.

We sought to make several contributions to the existing body of knowledge by research on organizational politics in non-western settings, and it is a culture-specific study which has explored the consequences of organizational politics. ${ }^{8}$ According to the authors best of knowledge, this is the firstever study which has documented the response of lowranked employees in the shape of interpersonal deviance and organizational deviance when they experience organizational politics in South Asian Context. We also provided empirical evidence for a positive relationship between organizational politics and interpersonal deviance and inverse relationship between politics and organizational deviance. Furthermore, job stress-triggered through organizational politics has also been tested empirically. This study was carried out in a collectivist culture where individuals may have a sensitivity to the stress. Asian societies are mostly collectivist in nature, and individuals here may have a different level of a tendency towards experiencing stress. More specifically, there is limited empirical research on the resilience of lower-level employees. Organizational politics encompasses various political behaviors, and one of these is concerned with the raises in pay and policies, hence, procedural injustice can be a meaningful predictor of organizational deviance, ${ }^{32}$ thus this study has attempted to address the future call of ${ }^{33}$ by investigating the impact of organizational politics as a predictor of deviance, both interpersonal 
and organizational. This study has also anticipated the research call of researchers for systematic evaluation of employee worked related issues which can be overcome for quality service delivery. ${ }^{34}$

\section{Organizational Politics}

The increased attention of scholars in organizational politics from the early $1960 \mathrm{~s}^{1,22}$ induced several definitions, and previous researchers have observed it from diverse perspectives. Organizational politics is a person's perceptions of political actions for instance favoritism, overpowering or competing individuals and the manipulation of policies of organization for the promotion of their personal interest without any concern for the prosperity and well-being of others or their organization. These activities encompass actions such as hiding new information from colleagues, enforcing not to implement policies, strategies, and procedures properly, using sweet dialogue to attain favors, shifting mistake, and criticizing others. These activities can cover three dimensions ${ }^{35}$ such as "general political behavior" in which employees tend to attain their desired outcomes through self-centered behaviors, second one is "go along to get ahead in which employees show quietness and perform passively for their personal benefits and the last dimension covers the interference of union members in pay and promotion policies. Such manipulations cannot be implemented alone without powerful supporters ${ }^{36}$ ultimately no one, except the union members.

Such behaviors are either legitimate or illegitimate ${ }^{37}$ however in this study we have considered only the illegitimate (non-sanctioned) tactics of politics (e.g., manipulation, control of information, blaming or attacking others, using surrogates) which entail undesirable social behaviors and those deviate from organizational goals and norms. ${ }^{38}$ Previous researchers ${ }^{1,4}$ have recognized the negative consequences of such behaviors at individual ${ }^{39}$ and organizational level such as lesser performance and decreased Organizational Citizenship Behavior, ${ }^{40}$ reduction in morale, increase in interpersonal conflict, and work withdrawal behaviors. Organizational politics has been recognized as a cause of psychological and physical strain, certainly, who may have been negatively harmed by political actions, perceive it to be a negative impact in organizations,

\section{Interpersonal And Organizational Deviance}

A voluntary behavior which threatens the well-being of an organization and its member is labeled as deviance. ${ }^{41,42}$
Deviance is employee's "voluntary behavior that violates significant organizational norms and in so doing threatens the well-being of an organization, its members, or both" cited in, ${ }^{43}$ and it can cost heavily. ${ }^{43}$ This workplace deviant behavior is composed of two types, namely, organizational deviance and interpersonal deviance. ${ }^{44}$ Interpersonal deviance is composed of behaviors shown by organizational members with the intention to harm the individuals by activities such as political deviance, gossiping, and aggression while organizational deviance refers to deviant behaviors directed toward the organization, examples of which include tardiness, wasting organizational resources, and stealing from the organization. ${ }^{41}$ This target-based, two-family perspective of deviance is consistent with past studies pertaining to negative organizational behaviors which are termed as anti-social behavior ${ }^{45}$ and misconduct at work. ${ }^{46}$ Deviant behavior includes sabotaging, stealing or theft, misuse of organizational resources, and accepting kickbacks. ${ }^{20}$ Thus, in the context of developing countries such as Pakistan, misuse of time/resources and withdrawal appears to be the most threatening forms which exist in public sector organizations ${ }^{20,41}$ and it has become a routine activity, ${ }^{20}$ which adopts various shapes from minor to major acts. ${ }^{41}$

\section{Job Stress}

Job stress is a combination of psychological and physiological responses triggered by work settings when an individual feels uncomfortable, unwanted, or threatened. ${ }^{47,48}$ Stress occurs in individuals if there is an imbalance between the demands and abilities in such a way that employees' knowledge, skills, abilities, and attitudes cannot cope with work pressures. Consequently, it may decrease the ability of employees to control and manage physiological and psychological stresses, and under such circumstances, they are unable to meet their duties and responsibilities as a member of an organization. ${ }^{47,49}$

However, stress is not always necessarily a negative phenomenon. In the literature, stress has been divided into two major types: eustress (good stress) and distress (bad stress). ${ }^{50}$ In this study, we have considered the negative side of stress (distress) due to its nexus with the various drastic consequences at the individual and organizational level. Such negative consequences include reduced efficiency, a lack of concern for the organization and colleagues, loss of responsibility, ${ }^{51}$ lower job satisfaction, decreased organizational commitment and employee withdrawal behavior. ${ }^{52-55}$ Due to the hazardous consequences 
of job stress, it is considered one of the biggest health and safety challenges. ${ }^{56,57}$ Various job related conditions determine the level of stress at workplace such as demands of the job (work load, working hours, work-life balance); control at work (the way of working, the importance of participation in decisions, and skill improvement); lack of support at work; poor relationships at workplace, mostly based on distrust; and changes in the job or organization, interpersonal or psychosocial features of the work environment. $^{58}$

\section{Resilience}

Resilience is considered as employee's adaptive and resource-utilizing capacity, which reflects the robustness to manage work-related setbacks, challenges, and pressures effectively. ${ }^{59}$ It also reflects the ability of individuals to bounce back and to beat the odds after experiencing adversity. ${ }^{60}$ More specifically, it shows persistence and flexible adaptation to take remedial actions in difficult situations and tolerance of negative emotions and failures. ${ }^{61-63}$ Resilience provides self-regulatory functions which refers to internal and/or transactional processes, that enable an individual to guide his or her goal-directed activities over time and across changing circumstances (contexts). ${ }^{64}$ Previous researchers from the field of psychology has emphasized that resilience contains self-regulatory functions which serve to attenuate the negative consequences arising from the uncontrollable environmental factors and protects the individuals to involve in anti-social behaviors. ${ }^{65,66}$ Thus, it is worthy to investigate the moderating effect of resilience in the nexus of the undesirable environment (politics) and anti-social behavior.

\section{Theory And Hypotheses}

Theoretical foundations of this study lie on social exchange theory $^{67}$ as reciprocity exists when one employee reacts to others or others at the workplace. The reciprocity in social exchange theory is based on the socioeconomic exchange of benefits, and negative reciprocity engages the propensity to return negative. Individuals tend to return negative reciprocity when they observe the actions or activities of others in organizations for the purpose of promotion of self-interest without concern for the prosperity and well-being of others staffs. ${ }^{68}$ This reciprocity to politics generates discourteous behavior among individuals which adversely impacts the outcomes of individuals and organization as an exchange relation. ${ }^{69,70}$ Theoretical pining of this study is also consistent with the
JD-R model ${ }^{71}$ which specifies that job demands relate positively and job resources relate negatively to workrelated strain which in turn leads to interpersonal and organizational deviance

When the job demands are very high, and resources to meet these demands are less, it brings exhaustion among employees $^{72}$ they tend to engage in discourteous behaviors.

The affective events theory (AET) proposed by Weiss and Cropanzano, ${ }^{73}$ also provides a theoretical lens which allows inducing relationships between politics, stress, and deviance at the workplace. Some specific events at the workplace trigger emotional reactions which develop specific attitudes and behaviors. Negative events in the shape of politics at workplace may trigger negative emotions among employees ${ }^{74}$ which can reduce individual's resources ${ }^{75}$ enabling the individuals to cope with politics through discourteous behaviors in the shape of interpersonal deviance and organization deviance. Emotions have a significant role in stress at work as emotions response instantly to situations which are supposed as stressful to an employee. Work environment hypothesis ${ }^{76}$ also explains the underlying cause behind the involvement of lower-level employees in politics. Involvement of lowerlevel employees in politics can be due to the prevailing environmental conditions in public sector organizations which have high power distance at organizational hierarchy. ${ }^{9}$ Moreover transactional theory of stress ${ }^{77,78}$ also provides support for this study as a stressor leads to strain only when the perceived threat to the self exceeds one's perceived level of coping resources. So lower level individuals might experience stress when they feel themselves in a position where they are incompetent to defend the politics of other union members.

\section{Relationship Of Politics, Stress And Deviant Behavior}

Organizational politics encompasses various political behavior, and one of these is concerned with the raises in pay and policies, hence, such political behaviors in the shape of procedural injustice can be a meaningful predictor of organizational deviance ${ }^{32}$ so any form of injustice from organization, supervisor or co-worker might generate stronger direct and indirect effects with deviant behaviors directed back to the originating source. ${ }^{33}$ Deviance in the shape of interpersonal and organizational deviance is quite high and conspicuous in public sector organizations. ${ }^{20}$ 
Political perceptions of individuals have significant consequences on a person's emotional states, and outcomes these effects are not only linked with individual level but also with organizational level outcomes. ${ }^{79}$ Politics is a negative phenomenon, and it drives individuals away from those behaviors which can be beneficial for the organizations. ${ }^{80}$ Thus it can be assumed that:-

H1a: Organizational politics significantly predict interpersonal deviance in lower-level employees

H1b: Organizational politics significantly predicts organizational deviance in lower-level employees

Political perceptions of organizations are negatively connected with the attitudinal outcomes and behavior of individuals ${ }^{81}$ such political perceptions are a cause of stress that builds stressor among the individuals within organizations. ${ }^{82}$ Organizational politics is a critical source of stress at workplace, this stress generating phenomena when prevails in the mind of employees and they perceive that decisions within the organizations are being driven by the self-serving to safeguard personal interest. ${ }^{83}$ In the presence of organizational politics, individuals strongly believe that their organization implicitly support "working behind the scenes. ${ }^{84}$ Political behaviors are inborn features inherited in the normal functioning of organizations, ${ }^{85}$ and thus organizational politics is considered as a negative feature ${ }^{84}$ which can reinforce severe negative consequences, such as stress, low level of commitment, increased turnover intentions, reduced job satisfaction. ${ }^{86}$
Stress at a job can induce uncivil behaviors, which further can elicit more stress and resultantly it can trigger more uncivil behaviors which can be harmful to individuals and organizations. Job stress is positively associated with numerous negative employees' outcomes, including absenteeism, voluntary turnover, and burnout. It causes vicious effects on job satisfaction, job engagement, productivity, emotional well-being, health, and costs both employees and organizations in terms of physiological, psychological, and economic loss. ${ }^{87,88}$ The JD-R model provides sufficient support for arousal of job stress among individuals because of multiple factors including workload, complex tasks, lack of relevant skills and training, less autonomy, lack of decision making authority, lack of two way communication, job insecurity, lack of development opportunities, insufficient rewards, ineffective management, role ambiguity, role conflict, harassment and bullying. ${ }^{88-90}$ However interpersonal conflicts are much more common stressors than customers, co-workers or workload stressors. ${ }^{91}$ When job stress disrupts one's equilibrium, individuals often deviate from their normal behavior patterns, which in turn affect their work outcomes. ${ }^{92}$ Stress at work (work-related stress or job stress) is the emotional response that happens when resources, capacities or necessities of employees never compete for job requirements ${ }^{93}$ and increasing stress at a job can stimulate organizational members to show negative behaviors (Figure-1). Stress exists within all professions of life, ${ }^{94}$ and it can induce drastic consequences in the shape of counterproductive work behaviors. Thus it can be hypothesized that:-

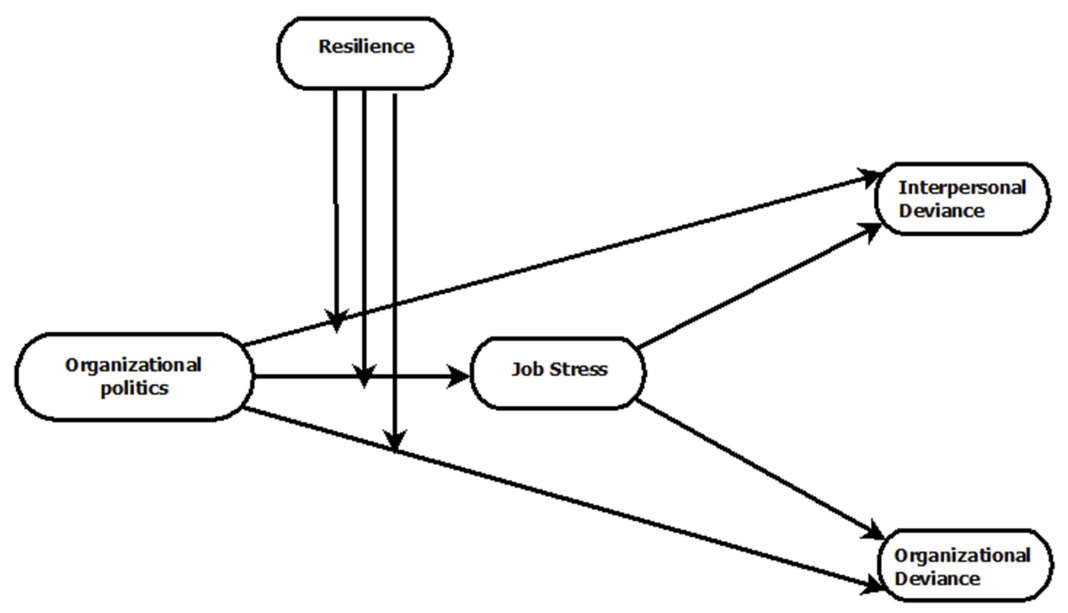

Figure I Framework. 
H2a: Lower level employees induce job stress when they experience politics

H2b: Lower level employees show interpersonal deviance when they experience stress at workplace

H2c: Lower level employees show organizational deviance when they experience stress at workplace.

H3a: Relationship between organizational politics and interpersonal deviance is mediated by job stress

H3b: Relationship between organizational politics and organizational deviance is mediated by job stress

\section{Moderating Role Of Resilience}

Although a variety of personal resources can attenuate the drastic consequences of politics in this study, we have considered only a resilience factor. Resilience, being the ability to bounce back, might protect individuals from psychological damage and involving in antisocial behaviors while experiencing politics because resilient individuals have the capability to resolve the challenging situations adequately. ${ }^{61}$ Resilience is a resource, and individuals rich in resources are less vulnerable to stress because they mobilize their resources to combat stress. ${ }^{95}$ Human beings are adaptive and figure out the ways to get rid of a stressful situation by using their resources. They get inside support from their personal and psychological resources and outside facilitation from their social resources. If these resources are good enough to counterattack demands arising from the external environment, people succeed to extract themselves from a difficult or harmful situation or at least they are able to tolerate the loss aroused from the situation.

Individuals who engage in anti-social or deviant behaviors lack 'self-control ${ }^{96}$ indeed, resilience provides a selfregulatory function against this personal deficit. Resilient employees might experience less stress due to the selfregulatory function of resilience. ${ }^{77}$ Less resilient employees may suffer from severe stress if they consider the situation as highly threatening, but the resulting situation can be quite different and healthy if individual interprets the situation as a challenge and feels the possession of required resources to deal with the situation and surmount the challenge. Resilient employees tend to cope with problems by adopting problem-based coping strategy when they feel themselves resourceful enough to deal problem and sense a complete control over the actual situation. ${ }^{77,78}$
Thus, resilience in the shape of personal resources can provide some sense of control over the environment ${ }^{97}$ enabling the individuals to cope with poisonous effects of politics in the shape of stress and deviance (Figure-1). On the basis of the above argument, it can be predicted that:-

H4a: Resilience moderates the relationship between organizational politics and interpersonal deviance

H4b: Resilience moderates the relationship between organizational politics and organizational deviance

H4c: Resilience moderates the relationship between organizational politics and job stress.

\section{Methods}

\section{Participants And Procedure}

The current study revolves around the premises of positivist philosophy. Respondents were public sector employees of the largest electric utility company of Pakistan (MEPCO/ WAPDA). Data were collected cross-sectionally through selfadministrated questionnaires. This research design facilitates a quantifiable data collection through questionnaires or by structured interviews on more than one case and at a single point in time. ${ }^{98}$ Only low-ranked employees were targeted to collect the data. Due to higher power distance, employees working at lower levels of the organizational hierarchy are less likely to be able to connect themselves with the management of the organization and hence they might experience political behavior at great. ${ }^{99}$ Stratified sampling technique ${ }^{98,100}$ was used to construct the sample. The motive behind using this probability sampling in this study was to minimize sampling error to avoid over and under-representation of sample. ${ }^{98}$ On the basis of the geographical distribution of the company (MEPCO), eight strata's were considered/framed to cover the entire population. Each stratum was called Circle, which was defined by the MEPCO itself on the geographical distribution of the respondents. Fifty lower-level employees from each circle were approached, briefed about the study and questionnaires were handed over to them by the research team. A total of 400 respondents were approached, and this sample size is large enough to draw a conclusion regarding the population on the basis of sample. ${ }^{101,102}$ From the total distributed 400 questionnaires, 359 were received back, questionnaires having missing values larger than $5 \%$ were discarded, whereas for other cases Hot deck imputation method was applied to handle missing data, and each missing value was replaced with an observed 
response from a respondent with similar characteristic, and at the end 340 questionnaires were considered for final data analysis, and hence the response rate remained at $85 \%$.

\section{Scale Development}

A five-point Likert scale ranging from strongly agree (5) to strongly disagree (1) was used to rate responses. Established literature was consulted for scale development, and independent variable in this study i.e., organizational politics was assessed on the basis of scale developed by. ${ }^{83}$ Nine items from this scale were adapted for this study and sample items for this scale were "when it comes to paying raises and promotion decisions, policies are irrelevant," and "Agreeing with powerful employees is the best alternative in this organization." Job stress (mediating variable) was assessed on the basis of nine items scale developed by, ${ }^{103}$ and sample items include " $M y$ job irritates me more than it should." Similarly, the dependent variable deviance was measured in two dimensions, ie, interpersonal deviance and organizational deviance. The interpersonal deviance was assessed with seven items, whereas organizational deviance was measured through 12 items scale, developed by. ${ }^{44}$ Sample items for interpersonal deviance include, "At the workplace, I have made fun of someone" whereas organizational deviance items include, "at the workplace, I waste too much time instead of working." The moderating variable Resilience was assessed on the basis of 5 items, adopted from ${ }^{104}$ and recently used by De Clercq and Belausteguigoitia, ${ }^{8}$ Sample items are, "I learn from my mistakes and getter better," "I find ways to handle unexpected situations". All the responses were self-reported, and thus, the possibility of common method bias ness was likely to shatter the results, but using self-reported and single-source measures in management research is common. ${ }^{105}$

However, we used several measures to reduce the possibility of common method bias ness, firstly we assured the respondents regarding confidentiality, and they were asked to rate the options honestly. Some items were also reverse coded to avoid monotonic responses. ${ }^{106}$ In addition to this, the research model of this study was divided into different sections and mediating, dependent, and independent variables were placed in different positions within the questionnaire. $^{107}$ This ensures that respondents cannot easily combine the related items and produce the correlation which is needed to generate a common method variance biased pattern in the responses. ${ }^{108}$

\section{Data Analysis}

Keeping in view complex relationships in current research directions, more sophisticated multivariate data analysis methods were required ${ }^{109}$ and thus variance-based structural equation modeling (PLS-SEM) has been used. The relationships have been estimated on the basis of the measurement model and structural model. ${ }^{110}$ Here Smart PLS 3.2.7 $7^{111}$ was used due to several reasons; here theory is less developed, ${ }^{110}$ and PLS-SEM works efficiently with complex models, and it makes practically no assumptions about the underlying data (for example, in terms of data distributions. In PLS-SEM, there is no identification issue with small sample sizes, and it generally achieves high levels of statistical power with small sample sizes.

\section{Demographic}

Data regarding gender, marital status, employment status, qualification and length of service was collected through

Table I Demographic Characteristics Of Respondents $(n=340)$

\begin{tabular}{|c|c|c|}
\hline Description & Frequency & Percent \\
\hline \multicolumn{3}{|l|}{ Gender } \\
\hline Male & 322 & 94.7 \\
\hline Female & 18 & 5.3 \\
\hline \multicolumn{3}{|l|}{ Marital status } \\
\hline Single & 239 & 70.3 \\
\hline Married & 101 & 29.7 \\
\hline \multicolumn{3}{|l|}{ Employment status } \\
\hline Permanent & 251 & 73.8 \\
\hline Contractual & 89 & 26.2 \\
\hline \multicolumn{3}{|l|}{ Qualification } \\
\hline Intermediate & 39 & 11.5 \\
\hline Graduation & 274 & 80.6 \\
\hline Master & 27 & 7.9 \\
\hline \multicolumn{3}{|l|}{ Age (years) } \\
\hline 22 Years & 39 & 11.5 \\
\hline 23 Years & 26 & 7.6 \\
\hline 24 Years & 103 & 30.3 \\
\hline 25 Years & 74 & 21.8 \\
\hline 26 Years & 52 & 15.3 \\
\hline 27 Years & 46 & 13.5 \\
\hline \multicolumn{3}{|l|}{ Experience (years) } \\
\hline I Years & 20 & 5.9 \\
\hline 2 Years & 152 & 44.7 \\
\hline 3 Years & 72 & 21.2 \\
\hline 4 Years & 50 & 14.7 \\
\hline 5 Years & 46 & 13.5 \\
\hline
\end{tabular}


the demographic section of the questionnaire, and it was observed that majority of the respondents were male, single, permanent job status and having graduation degree (Table 1). Additionally, most of the respondents were young having age of 24 years and length of service covering two years.

\section{Assessment Of Measurement Model}

Results of Structural Equation Modeling (SEM) through Smart PLS 3.2.0 have been reported by covering the dimensions of measurement and structural models. Keeping in view the constructs and nature of relationships, a reflective measurement model was established. ${ }^{112}$ Measurement model has been assessed through reliability and validity (Table 2), construct reliability was assessed through Cronbach's Alpha, rho-A and composite reliability, ${ }^{113}$ whereas indicator reliability was measured on the basis of outer loadings. On the other hand, validity was assessed in two dimensions, Average variance extracted (AVE) and outer loadings ${ }^{114,115}$ were used for convergent validity, ${ }^{116}$ and discriminant validity was assessed through, cross-loadings, Fornell and Larcker, (1981) Criteria and HTMT. ${ }^{112}$ All the "alpha coefficients, CR estimates, values of rho-A, and average variance extracted (AVE) were above their cutoff values ${ }^{112,118}$ confirming the reliability and validity of the measurement model.

Convergent validity is used to identify how an indicator is positively correlated with other indicators under the same umbrella of theoretical framework. ${ }^{114}$ Generally, the

Table 2 Indicator Reliability, Cross Loadings, VIF, Alpha, rho-A, CR And AVE

\begin{tabular}{|c|c|c|c|c|c|c|c|c|}
\hline Constructs & Indicator & $\begin{array}{l}\text { Indicator } \\
\text { Reliability }\end{array}$ & $\begin{array}{l}\text { Cross } \\
\text { Loadings }\end{array}$ & VIF & Alpha & rho-A & $\begin{array}{l}\text { Composite } \\
\text { Reliability }\end{array}$ & AVE \\
\hline Interpersonal deviance & $\begin{array}{l}\text { IDI } \\
\text { ID2 } \\
\text { ID3 } \\
\text { ID4 } \\
\text { ID5 } \\
\text { ID6 } \\
\text { ID7 }\end{array}$ & $\begin{array}{l}0.759 \\
0.794 \\
0.715 \\
0.642 \\
0.681 \\
0.789 \\
0.859\end{array}$ & $\begin{array}{l}0.759 \\
0.794 \\
0.715 \\
0.642 \\
0.681 \\
0.789 \\
0.859\end{array}$ & $\begin{array}{l}3.145 \\
3.193 \\
1.788 \\
2.196 \\
1.440 \\
3.081 \\
3.196\end{array}$ & 0.87 & 0.88 & 0.90 & 0.57 \\
\hline Job stress & $\begin{array}{l}\text { JSI } \\
\text { JS2 } \\
\text { JS3 } \\
\text { JS4 } \\
\text { JS5 } \\
\text { JS6 } \\
\text { JS7 } \\
\text { JS8 }\end{array}$ & $\begin{array}{l}0.732 \\
0.791 \\
0.754 \\
0.812 \\
0.757 \\
0.874 \\
0.702 \\
0.521\end{array}$ & $\begin{array}{l}0.732 \\
0.791 \\
0.754 \\
0.812 \\
0.757 \\
0.874 \\
0.702 \\
0.521\end{array}$ & $\begin{array}{l}2.156 \\
2.455 \\
1.864 \\
3.248 \\
1.987 \\
3.029 \\
2.486 \\
1.221\end{array}$ & 0.88 & 0.89 & 0.91 & 0.56 \\
\hline Organizational deviance & $\begin{array}{l}\text { ODI } \\
\text { OD2 } \\
\text { OD3 } \\
\text { OD4 } \\
\text { OD5 } \\
\text { OD6 } \\
\text { OD9 } \\
\text { OD10 } \\
\text { OD11 } \\
\text { OD12 }\end{array}$ & $\begin{array}{l}0.526 \\
0.829 \\
0.808 \\
0.682 \\
0.736 \\
0.752 \\
0.818 \\
0.708 \\
0.757 \\
0.684\end{array}$ & $\begin{array}{l}0.526 \\
0.829 \\
0.808 \\
0.682 \\
0.736 \\
0.752 \\
0.818 \\
0.708 \\
0.757 \\
0.684\end{array}$ & $\begin{array}{l}2.119 \\
3.254 \\
2.295 \\
2.082 \\
3.040 \\
3.335 \\
2.766 \\
2.920 \\
2.478 \\
2.481\end{array}$ & 0.92 & 0.90 & 0.92 & 0.54 \\
\hline Organizational politics & $\begin{array}{l}\text { OPI } \\
\text { OP2 } \\
\text { OP4 } \\
\text { OP6 } \\
\text { OP7 } \\
\text { OP8 } \\
\text { OP9 }\end{array}$ & $\begin{array}{l}0.668 \\
0.686 \\
0.637 \\
0.594 \\
0.757 \\
0.843 \\
0.713\end{array}$ & $\begin{array}{l}0.668 \\
0.686 \\
0.637 \\
0.594 \\
0.757 \\
0.843 \\
0.713\end{array}$ & $\begin{array}{l}1.721 \\
1.533 \\
1.427 \\
1.390 \\
1.951 \\
2.976 \\
1.697\end{array}$ & 0.82 & 0.84 & 0.87 & 0.50 \\
\hline
\end{tabular}


convergent validity is measured through outer loadings and Average Variance Extracted in reflective measurement models. In the first attempt items having outer loadings below 0.708 were checked against each variable. Indicators JS-9 from job stress and OP-3 and OP-5 were removed from the organizational politics due to weak outer loadings. However, OP-1, OP-2, OP-4, and OP-6 were retained in spite of low outer loadings because AVE was within the threshold limit in the presence of these indicators. No indicator from interpersonal deviance was removed, however, and indicators OD-7 and OD-8 were removed from organizational deviance (dependent variable) due to weak outer loadings. Cross loadings, Fornell and Larcker, (1981) ${ }^{117}$ criteria and HTMT results (Tables 2 and 3 ) confirmed that all the constructs are different from other constructs of the model. ${ }^{119}$ Here the square root of AVE of each latent variable was higher than the correlations among the latent variables". ${ }^{110,114}$ Cross loadings of indicators of each construct were higher on the same constructs as compared with the other indicators. In addition to this, HTMT values were less the threshold value of 0.85 , confirming the discrepant validity of the model. ${ }^{120}$

\section{Assessment Of Structural Model}

Assessment of structural model in this study is based on linearity (Table 2), Coefficient of determination (Level of $\mathrm{R}^{2}$ ) (Table 3 ), effect size $\left(\mathrm{f}^{2}\right)$, the predictive relevance $\mathrm{Q}^{2}$ (Table 3 ) and path significance. ${ }^{118}$ Multicolinearity can decrease the analytical influence of predicting variables, ${ }^{115}$ therefore to obtain the best parameter estimation assessment of multicollinearity was tested, and here almost all values were less than the cut point value of $\pm 5.0 .{ }^{118}$ The coefficient of determination represents the exogenous latent variables' combined effects on the endogenous latent variable. Coefficient of determination (denoted by $\mathrm{R}^{2}$ ) shows the percentage of change in dependent variable due to the independent variable, here in the model it is cleared that $24 \%$ change in interpersonal deviance is being explained by organizational politics and job stress. Similarly, $35 \%$ change in job stress is being explained by organizational politics, and finally, a $4 \%$ change in organizational deviance is being explained by organizational politics and job stress collectively. Effect size $\left(\mathrm{f}^{2}\right)$ is assessed as small (0.02), medium $(0.15)$ and large $(0.35) .{ }^{121}$ Here near to medium effect size has been observed against interpersonal deviance (0.12) and small effect organizational deviance (0.04) due to job stress, the effect size predicting interpersonal deviance and organizational deviance due to organizational politics was also very small, 0.02 and 0.01 respectively. However, the effect size of job stress due to organizational politics was large (0.55). Predictive accuracy was measured through the coefficient of determination $\left(\mathrm{R}^{2}\right)$ whereas predictive relevance was assessed on the basis of $\mathrm{Q}^{2}$ value, ${ }^{122,123}$ and it indicated a predictive relevance of reflective endogenous latent variables (Table 3).

\section{Discussion And Findings}

Relationship of organizational politics and interpersonal deviance was found significant (H1a) $(\beta=0.161, t=2.368$, $p<0.05)$. These results confirm that employees who experience politics at workplace tend to involve in deviant workplace behavior in the shape of interpersonal deviance such as they tend to make fun of their fellow beings, say something hurtful to their colleagues or even tend to act rudely. These findings are supported by the recommendations of Vigoda-Gadot and Talmud, ${ }^{124}$ that politics, in the shape of influence and power have an impact on each individual ${ }^{39}$ and among youth tendency to involve in antisocial behaviors exist at a moderate level. ${ }^{125}$ On the other hand, the impact of organizational politics on organizational deviance (H1b) was found insignificant (Table 4). These findings indicate inconsistency from the past literature as in the context of developing countries misuse of time/resources and withdrawal in public sector organizations can prevail very commonly. ${ }^{20,41}$ This finding is also inconsistent with the previous research ${ }^{125}$ that among youth tendency to involve in antisocial behaviors exist at a moderate level. These results are very interesting and depict that individuals experiencing political behavior at the workplace don't get involved in organizational deviance. This outcome shed light on the perception of individuals working in public

Table 3 Fornel-Larcker (I98I) Criteria, HTMT, Coefficient Of Determination And Predictive Relevance

\begin{tabular}{|l|l|l|l|l|l|l|l|}
\hline Construct & ID & JS & OD & OP & $\mathbf{R}^{\mathbf{2}}$ & $\mathbf{R}^{\mathbf{2}}$ Adjusted $^{\mathbf{2}}$ & $\mathbf{Q}^{\mathbf{2}}$ \\
\hline ID & $\mathbf{0 . 7 5 1}$ & 0.521 & 0.104 & 0.435 & 0.239 & 0.234 & 0.12 \\
JS & 0.471 & $\mathbf{0 . 7 4 9}$ & 0.150 & 0.680 & 0.354 & 0.352 & 0.18 \\
OD & 0.069 & 0.181 & $\mathbf{0 . 7 3 5}$ & 0.108 & 0.04 & 0.034 & 0.01 \\
OP & 0.384 & 0.595 & 0.042 & $\mathbf{0 . 7 0 4}$ & - & - & - \\
\hline
\end{tabular}

Note: Bold values indicate significance in establishing discriminant validity. 
Table 4 Hypotheses Testing

\begin{tabular}{|c|c|c|c|c|c|}
\hline \multicolumn{2}{|c|}{ Hypotheses } & \multirow{2}{*}{$\frac{\beta}{0.161}$} & \multirow{2}{*}{$\begin{array}{l}\boldsymbol{t} \\
2.368\end{array}$} & \multirow{2}{*}{$\frac{P}{0.02}$} & \multirow{2}{*}{$\begin{array}{l}\text { Status } \\
\text { Supported }\end{array}$} \\
\hline $\mathrm{HIa}$ & $\mathrm{OP} \rightarrow \mathrm{ID}$ & & & & \\
\hline $\mathrm{HIb}$ & $\mathrm{OP} \rightarrow \mathrm{OD}$ & -0.102 & 0.970 & 0.33 & Not Supported \\
\hline $\mathrm{H} 2 \mathrm{a}$ & $\mathrm{OP} \rightarrow \mathrm{JS}$ & 0.595 & 17.213 & 0.00 & Supported \\
\hline $\mathrm{H} 2 \mathrm{~b}$ & $\mathrm{JS} \rightarrow \mathrm{ID}$ & 0.375 & 5.886 & 0.00 & Supported \\
\hline $\mathrm{H} 2 \mathrm{c}$ & $\mathrm{JS} \rightarrow \mathrm{OD}$ & 0.242 & 2.210 & 0.02 & Supported \\
\hline \multicolumn{2}{|c|}{ Hypotheses } & Indirect effect & Total effect & VAF & Status \\
\hline $\mathrm{H} 3 \mathrm{a}$ & $\mathrm{OP} \rightarrow \mathrm{JS} \rightarrow \mathrm{ID}$ & 0.22 & 0.38 & $58 \%$ & Supported \\
\hline $\mathrm{H} 3 \mathrm{~b}$ & $\mathrm{OP} \rightarrow \mathrm{JS} \rightarrow \mathrm{OD}$ & 0.14 & 0.04 & $350 \%$ & Supported \\
\hline
\end{tabular}

sector organizations at a lower level of the hierarchy. It might be due to the reason that individuals at lower of hierarchy in an organization might possibly have a higher level of commitment with the organization; increasing unemployment rate among youth can also be a reason for this outcome. Additionally, it might be due to the identity of lower-level employees, which is based on the social system due to emotional dependence of individual on organizations and institutions. ${ }^{9}$ However these inconsistencies require further investigation in future.

$\mathrm{H} 2 \mathrm{a}$ was found significant $(\beta=0.595, t=17.213, p<0.05)$. These results confirm that employees who experience political behavior at the workplace also experience jobs stress, such as feeling nervousness, irritation, and tight feelings at the workplace. These findings are in tune with the previous researchers ${ }^{81,83,96}$ that political perceptions of organizations are negatively connected with the attitudinal outcomes and behavior of individuals. Findings of ${ }^{12}$ indicate that the prevalent perception of politics, in turn, lead employees to feel stressed has also been endorsed by this study. While organizational politics is not an authorized behavior within organizations, this empirical research has substantiated the notion that politics perceptions are a cause of stress that builds stressor among individuals. ${ }^{82}$

$\mathrm{H} 2 \mathrm{~b}$ was formulated to check the impact of job stress on interpersonal deviance. Here the statistics were significant $(\beta=0.375, \mathrm{t}=5.885, \mathrm{p}<0.05)$. It has been proved that employees who experience stress at the workplace, such as feeling nervousness, irrigation, and tight feelings at the workplace may indulge in interpersonal deviance at the workplace. Impact of job stress on organizational deviance $(\mathrm{H} 2 \mathrm{c})$ was found significant (Table 4) implying that employees experiencing stress at the workplace have tendency to indulge in organizational deviance at workplace such as they take property from work without permission, waste too much time instead of working, falsified a receipt to get reimbursed more money then spent, enjoy unnecessary breaks or even come late to office, take an additional or unnecessary longer breaks or even put little effort in work. These findings are in line with the past literature that stress at work leads to negative consequences for employees and institutions ${ }^{18}$ and increasing stress at job motivates individuals towards negative behavior such as stealing, verbal harassment, and sabotage. ${ }^{126,127}$

Mediation ( $\mathrm{H} 3 \mathrm{a})$ was assessed by calculating the variance accounted for (VAF) approach. ${ }^{102,128}$ VAF shows higher levels of statistical power compared with the Sobel test. $^{102}$ VAF determines the size of the indirect effect in relation to the total effect (direct effect+ indirect effect). Here the value of VAF was 58\%, assuming job stress partially mediates the relationship between organizational politics and interpersonal deviance. For mediating role of job stress between the relationship of organizational politics and organizational deviance, the value of VAF was greater than $100 \%$ which shows a suppressor effect, and it can be assumed that job stress fully mediated the relationship between organizational politics and organization deviance.

These findings are in line with the findings of Mursali et al, ${ }^{93}$ that anxiety at work (business-related or occupation anxiety) is the enthusiastic reactions and this work stress inspires individuals to show negative conduct as a person may suffer from severe stress, anxiety or illness if he considers the situation as highly threatening and lack of resources to cope or tolerate the situation. Further Affective Event Theory also supports this argument, ${ }^{73}$ which explains the phenomena of emotional reactions to the specific events which occur at the workplace.

Moderating hypotheses ( $\mathrm{H} 4 \mathrm{a}, \mathrm{H} 4 \mathrm{~b}$, and $\mathrm{H} 4 \mathrm{c}$ ) which were formulated to test moderating impact of resilience between the relationships of organizational politics, interpersonal 


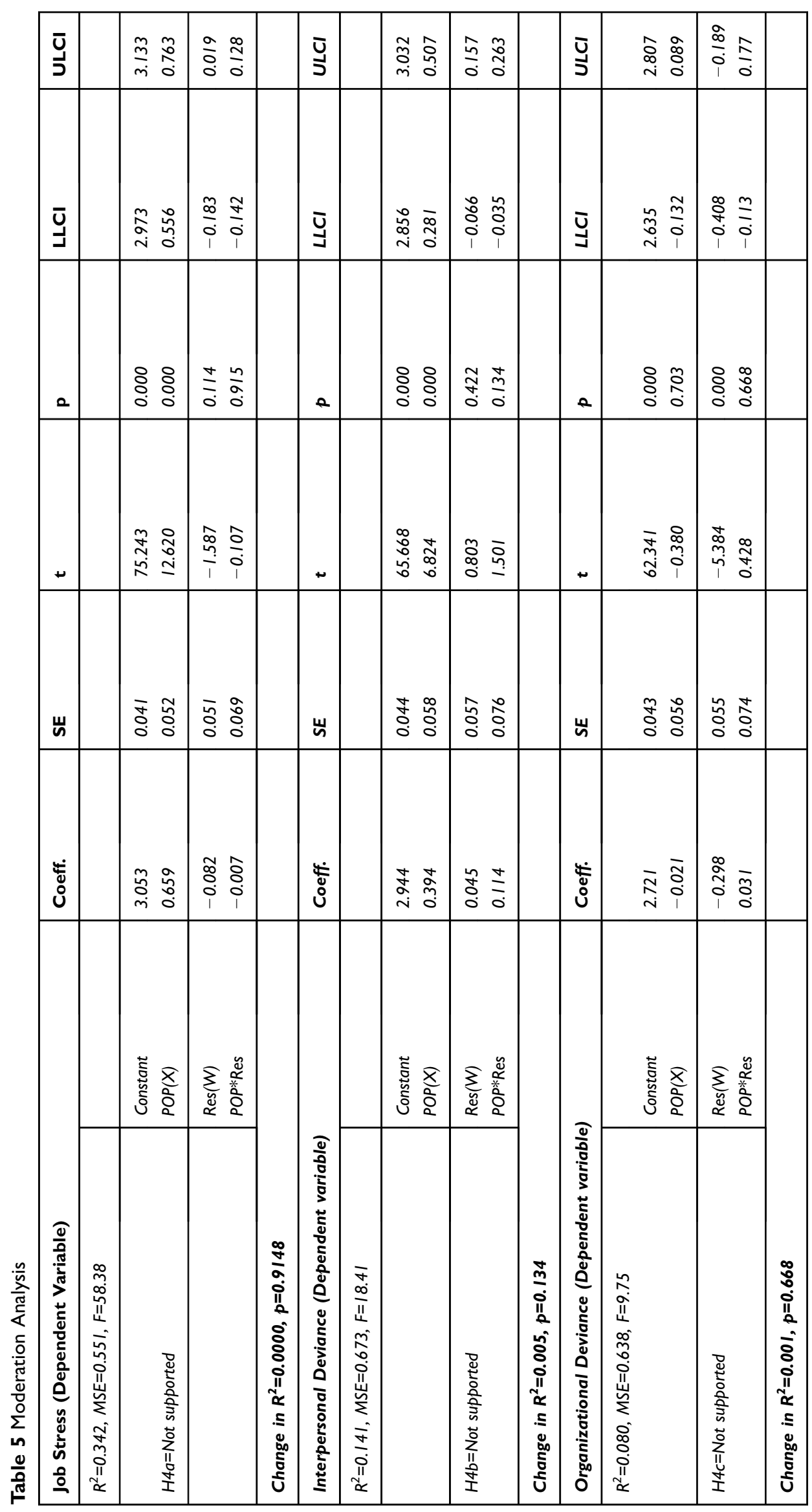


deviance, organizational deviance, and job stress respectively were not accepted due to insufficient evidence, and it has been found that resilience did not moderate the relationships (Table 5). The reason might be that respondents of this study were lower-level employees of public sector organizations and might possibly they lack resilience due to their lower order hierarchical position within the organizations as they have to obey their bosses, supervisors during most of the office hours. Resilient employees might tend to involve in constructive deviance in spite of the destructive side of deviance; thus, the insignificant moderating role of resilience might be due to this factor. ${ }^{129}$

Summarizing the findings, it can be sum-up that organizational politics within organizational circuits trigger interpersonal deviance and individuals tend to involve in deviant workplace behaviors, however they don't get involved in such antisocial behaviors directed towards the employer or organization, however this finding is inconsistent from the past literature, it requires further investigation in future. It has also been found that individuals experience stress in response to political behaviors at the workplace, such as feeling nervousness, irritation, and tight feelings at the workplace. ${ }^{81,83,96}$ More interestingly it has been observed that individuals tend to show deviant behaviors which are directed towards individuals and organizations when they experience stress triggered by organizational politics. Finally, it has been found that resilience did not moderate the relationships between politics and deviant behavior. The reason might be that respondents of this study were lowerlevel employees and resilient employees might tend to involve in constructive deviance in spite of destructive side of deviance; thus the insignificant moderating role of resilience might be due to this factor. ${ }^{129}$

\section{Conclusion}

On the basis of empirical findings of this study, it can be concluded that organizational politics is a predictor of interpersonal deviance among low-level workers. Organizational politics also brings job stress among workers, and this job stress further triggers interpersonal and organizational deviance. On the basis of this investigation it can also be concluded that lower-level employees in a high power distance country don't get involved in organizational deviance when they experience politics within organizational circuits, rather they get involved in activities aiming interpersonal deviance such as making fun of their fellow beings, say something hurtful to their colleagues, play a mean joke to their coworkers or even tend to act rudely. Further, the relationship of organizational politics has been found stronger with job stress as compared to other constructs of this study. Similarly, organizational politics showed a stronger relationship with interpersonal deviance as compared to organizational deviance. There is a possibility that differences in perceptions of moral events could be contributing to the mixed findings of the current study. ${ }^{130}$ Psychologically empowered employees are more likely to involve constructive deviance as compared to the destructive side of deviance; thus, the insignificant moderating role of resilience might be due to this factor. ${ }^{129}$

\section{Theoretical Contribution}

From a theoretical perspective, this study has several contributions; first, this study has made an attempt to investigate the impact of organizational politics on interpersonal deviance and organizational deviance in culture-specific studies to explore the consequences of organizational politics. ${ }^{8}$ This study was carried out in a collectivist culture where individuals may have a sensitivity to the stress. Asian societies are mostly collectivist in nature, as Pakistan is a collectivist culture-oriented country and individuals here may have a different level of tendency towards experiencing the stress, Similarly in high power distance subordinates may feel higher level of power gap due to centralization and they might involve themselves in political activities within the organization to gain power. ${ }^{131}$ This is the contribution of this study, and it has been confirmed that organizational politics bring interpersonal and organizational deviance as well as job stress. ${ }^{8}$ This study has contributed to insufficient literature which has investigated the relationship between organizational politics and behaviors. ${ }^{11}$ Organizational politics encompasses various political behavior, and one of these is concerned with the raises in pay and policies, hence, procedural injustice can be a meaningful predictor of organizational deviance, ${ }^{32}$ thus this study has attempted to address the future call of ${ }^{33}$ by investigating the impact of organizational politics as a predictor of deviance both interpersonal and organizational deviance.

\section{Practical Contribution}

This study has examined the impact of organizational politics on interpersonal and organizational deviance through the mediating role of job stress, and findings supported the argument that pervasiveness of political environment within the organization can trigger interpersonal deviance. This state of affairs can halt the productivity of employees in terms of performance, so management should introduce 
preventive measures to eradicate political behaviors within the organizational circuits. Further, this study has concluded that politics within the organizations promote stress among individuals; it must be controlled in order to avoid stressrelated costs. Keeping in view the quantum of poisonous effects brewing at the workplace due to politics in the shape of deviant behavior, awareness regarding such factors is fundamental in order to develop and implement effective intervention strategies. Organizations should also formulate policies and procedures to tackle the political behaviors within work settings. Resilience has not been proved as a moderator of the relationship between the relationships of organizational politics; interpersonal deviance, organizational deviance, and job stress. Management should introduce training, seminar, and refresher courses in order to boost the resilience of lower-level employees.

\section{Limitations And Future Directions}

Despite the contributions of the current study in highlighting how this study has addressed the specific gaps in a politicsstress-deviance relationship, particularly in developing country's context, there are some potential limitations pertaining to this investigation. Frist this is survey-based research with cross-sectional research design which often does not allow inferring causality among study constructs. ${ }^{132}$ The longitudinal research designs are generally considered to be more suitable designs for examining causal relationships. However, most of the academic research prefers cross-section research design due to resource constraint in the shape of time and cost. So in future researches following longitudinal design will help to establish cause and effect the relationship among organizational politics, stress, and deviance. Second data were collected from the lower-level employees of the largest public sector organization, and responses are based on self-perception, and thus a possibility of common method bias cannot be ignored in the data. ${ }^{133}$

Lower-level employees of a public sector organization were a population of this study, which is also a limitation of the study, in future other than lower-level employees can also be approached for data collection. In a public sector organization bureaucratic environment has a higher power distance which might be a cause of deviance, thus exploring the perception of employees of the private sector will bring important insights into the literature in future. There are three dimensions of politics, ${ }^{35}$ first one is, "general political behavior", employee 'self-centered behaviors to achieve desired outcomes, the second one is "go along to get ahead", in which employees show quietness and perform passively for their personal benefits, and the third one is, "pay and promotion policies", employee involvement in the application of policies and respond politically in the process of decision making, this study investigated organizational politics as a single dimension, and thus in future studies three dimensions of organizational politics must be kept under considerations. Further stress was investigated in general terms, so considering the physical and psychological stress in future studies will be an important avenue for future researchers. In future other variables such as Islamic work, ethics must also be included along with this framework, and their impact must be tested. Robinson and Bennett, ${ }^{41}$ reported a serious form of organizational deviance as "accepting kickbacks" or financial corruption and this dimension is most prevalent in developing Asian countries generally and in Pakistan specifically, ${ }^{20}$ So future studies investigating deviance among employees of the public sector in developing country should also consider accepting kickbacks as a dimension of counterproductive work behaviors in unionized organizations.

Economic crises trigger stress among the individuals and can be assumed that economic crisis can also be linked with organizational politics via stress; hence it would be interesting if future research considers the element of economic crises and its relationship with organizational politics. ${ }^{134}$ Previous studies indicate that stress is associated with mental health problems. Possibly, the consequences will be more severe within particular departments or among some categories of employees such as contractual workers and women, hence in future comparison of contractual and permanent workers along with male and females can also provide important insights. ${ }^{134}$

While previous researchers have typically take a destructive side of deviant behavior, which overlooks the potential for constructive deviance to challenge norms and drive healthy change in organizations, ${ }^{135,136}$ constructive side of deviance can also be an interesting avenue for future researches. Individuals having a higher level of work engagement might be less likely to engage in organizational deviant behavior overall, ${ }^{137}$ so work engagement can also be considered in future researches pertaining to deviance in lower-level employees.

\section{Ethics Statement}

This study was carried out only for educational purpose. This study is based on perceptions of respondents, and no experimental or other research design was followed. However, we had obtained written informed consent from every respondent at the time when questionnaires were completed. Moreover, respondents were not asked to disclose their name or any other 
information as a matter of confidentiality and their identity is anonyms. The protocol was approved by the ethics committee of Government College University Faisalabad, Pakistan.

\section{Acknowledgment}

We would like to acknowledge the feedback of anonymous respondents in this study.

Special thanks to the management of Smart PLS GmbH, Boenningstedt, Germany URL: www.smartpls.com for their favor and issuance of the license key to use Smart PLS 3.3.8. Ringle, C. M., Wende, S., and Becker, J.-M., 2015. "SmartPLS 3." Boenningstedt: SmartPLS GmbH. ${ }^{111}$

\section{Disclosure}

The authors report no conflicts of interest in this work.

\section{References}

1. Ferris GR, Kacmar KM. Perceptions of organizational politics. $J$ Manage. 1992;18(1):93-116.

2. Ferris GR, Adams G, Kolodinsky RW, Hochwarter WA, Ammeter AP. Perceptions of organizational politics: theory and research directions. In: The Many Faces of Multi-Level Issues. Emerald Group Publishing Limited. 2002:179-254.

3. Ferris GR, Hochwarter WA. Organizational politics. APA Handb Ind Organ Psychol. 2011;3:435-459.

4. Ferris GR, Hochwarter WA, Buckley MR. Theory in the organizational sciences: how will we know it when we see it? Organ Psychol Rev. 2012;2(1):94-106.

5. Rosen CC, Hochwarter WA. Looking back and falling further behind: the moderating role of rumination on the relationship between organizational politics and employee attitudes, wellbeing, and performance. Organ Behav Hum Decis Process. 2014;124(2):177-189. doi:10.1016/j.obhdp.2014.03.003

6. Rosen CC, Kacmar KM, Harris KJ, Gavin MB, Hochwarter WA. Workplace politics and performance appraisal: a two-study, multilevel field investigation. J Leadersh Organ Stud. 2017;24(1):20-38. doi:10.1177/1548051816661480

7. Ferris GR, Perrewé PL, Daniels SR, Lawong D, Holmes JJ. Social influence and politics in organizational research : what we know and what we need to know. Journal of Leadership \& Organizational Studies. 2017;24(1):5-19. doi:10.1177/ 1548051816656003

8. De Clercq D, Belausteguigoitia I. Mitigating the negative effect of perceived organizational politics on organizational citizenship behavior: moderating roles of contextual and personal resources. $J$ Manag Organ. 2017;23(5):689-708. doi:10.1017/jmo.2017.7

9. Hofstede G. National cultures in four dimensions: a research-based theory of cultural differences among nations. Int Stud Manag Organ. 1983;13(1-2):46-74.

10. Chinomona R, Chinomona E. The influence of employees' perceptions of organizational politics on turnover intentions in Zimbabwe's SME sector. South African J Bus Manag. 2013;44 (2):57-66. doi:10.4102/sajbm.v44i2.156

11. Landells EM, Albrecht SL. The positives and negatives of organizational politics: a qualitative study. J Bus Psychol. 2015. doi:10.1007/s10869-015-9434-5

12. Poon JML. Situational antecedents and outcomes of organizational politics perceptions. J Manag Psychol. 2003;18(2):138-155. doi:10.1108/02683940310465036
13. Kane-Frieder RE, Hochwarter WA, Ferris GR. Terms of engagement: political boundaries of work engagement-work outcomes relationships. Hum Relations. 2014;67(3):357-382. doi:10.1177/ 0018726713495068

14. Witt LA. Enhancing organizational goal congruence: a solution to organizational politics. J Appl Psychol. 1998;83(4):666. doi: $10.1037 / 0021-9010.83 .4 .666$

15. Ferris GR, Frink DD, Galang MC, Zhou J, Kacmar KM, Howard JL. Perceptions of organizational politics: prediction, stress-related implications, and outcomes. Hum Relations. 1996;49(2):233-266. doi:10.1177/001872679604900206

16. Witt LA, Andrews MC, Kacmar KM. The role of participation in decision-making in the organizational politics-job satisfaction relationship. Hum Relations. 2000;53(3):341-358. doi:10.1177/ 0018726700533003

17. Maslyn JM, Fedor DB. Perceptions of politics: does measuring different foci matter? J Appl Psychol. 1998;83(4):645-653. doi:10.1037/0021-9010.83.4.645

18. Agarwal UA. Examining perceived organizational politics among Indian managers: engagement as mediator and locus of control as moderator. Int J Organ Anal. 2016;24(3):415-437. doi:10.1108/ IJOA-07-2014-0786

19. Drory A, Meisler G. 13 emotion and emotional intelligence in organizational politics. Handb Organ Polit Look Back to Futur. 2016;319.

20. Bashir S, Nasir M, Qayyum S. Dimensionality of counterproductive work behaviors in public sector organizations of Pakistan. Public Organ Rev. 2012:357-366. doi:10.1007/s11115-012-0177-8

21. Bensimon HF. Violence in the workplace. Train Dev. 1994;48 (1):26-32.

22. Ferris GR, Frink DD, Gilmore DC, Kacmar KM. Understanding as an antidote for the dysfunctional consequences of organizational politics as a stressor 1. J Appl Soc Psychol. 1994;24(13):12041220. doi:10.1111/j.1559-1816.1994.tb01551.x

23. Gandz J, Murray VV. The experience of workplace politics. Acad Manag J. 1980;23(2):237-251.

24. Khattak SA, Bashir S. Evaluation of Union Commitment in Public sector Organizations of Pakistan: a time lagged study. Abasyn Univ J Soc Sci. 2018;11:1.

25. Ferris GR, Perrewé PL, Daniels SR, Lawong D, Holmes JJ. Social influence and politics in organizational research: what we know and what we need to know. J Leadersh Organ Stud. 2017;24(1):5-19. doi: $10.1177 / 1548051816656003$

26. Tattersall A. There is power in coalition: a framework for assessing how and when union-community coalitions are effective and enhance union power. Labour Ind a J Soc Econ Relations Work. 2005;16(2):97-112. doi:10.1080/10301763.2005.10669325

27. Martins P. Cronyism. Discussion paper. Bonn: IZA; 2010.

28. Rauh J. Predicting political influence on state ethics commissions: of course we are ethical—nudge nudge, wink wink. Public Adm Rev. 2015;75(1):98-110. doi:10.1111/puar.12290

29. MEPCO | Multan Electric Power Company. Available from: http:// www.mepco.com.pk/. Accessed September 22, 2018.

30. Norris P. Democratic Phoenix: Reinventing Political Activism. Cambridge University Press; 2002.

31. Kerrissey J, Schofer E. Labor Unions and political participation in comparative perspective. Social Forces; 2018. (June). doi:10.1093/ sf/soy044

32. Colquitt JA. On the dimensionality of organizational justice: a construct validation of a measure. J Appl Psychol. 2001;86(3):386.

33. Michel JS, Hargis MB. What motivates deviant behavior in the workplace? An examination of the mechanisms by which procedural injustice affects deviance. Motiv Emot. 2016. doi:10.1007/ s11031-016-9584-4

34. Ostrom AL, Parasuraman A, Bowen DE, Patricio L, Voss CA. Service research priorities in a rapidly changing context. J Serv Res. 2015;18(2):127-159. doi:10.1177/1094670515576315 
35. Haq IU. The impact of interpersonal conflict on job outcomes: mediating role of perception of organizational politics. Procedia-Social Behav Sci. 2011;25:287-310. doi:10.1016/j. sbspro.2011.10.549

36. Abbas M, Raja U. Impact of perceived organizational politics on supervisory-rated innovative performance and job stress: evidence from Pakistan. J Adv Manag Sci. 2014;2:2.

37. Kapoutsis I, Papalexandris A, Thanos IC, Nikolopoulos AG. The role of political tactics on the organizational context-career success relationship. Int J Hum Resour Manag. 2012;23(9):1908-1929. doi:10.1080/09585192.2011.610345

38. Miles A, Vaisey S. Morality and politics: comparing alternate theories. Soc Sci Res. 2015;53:252-269. doi:10.1016/j. ssresearch.2015.06.002

39. Shrestha AK, Mishra AK. Interactive effects of public service motivation and organizational politics on Nepali civil service employees' organizational commitment. Bus Perspect Res. 2015;3 (1):21-35. doi:10.1177/2278533714551862

40. Randall EV, Cooper BS, Hite SJ. Understanding the politics of research in education. Educ Policy. 1999;13(1):7-22. doi:10.1177/ 0895904899131002

41. Robinson SL, Bennett RJ. A typology of deviant workplace behaviors: a multidimensional scaling study. Acad Manag J. 1995;38 (2):555-572.

42. Sackett PR, DeVore CJ. Counterproductive behaviors at work. In: International Handbook of Work Psychology. Sage Publications; 2001:145

43. Liao H, Joshi A, Chuang ASP. Sticking out like a sore thumb: employee dissimilarity and deviance at work. Pers Psychol. 2004;57(4):969-1000. doi:10.1111/j.1744-6570.2004.00012.x

44. Bennett RJ, Robinson SL. Development of a measure of workplace deviance. J Appl Psychol. 2000;85(3):349.

45. Robinson SL, O'Leary-Kelly AM. Monkey see, monkey do: the influence of work groups on the antisocial behavior of employees. Acad Manag J. 1998;41(6):658-672.

46. Vardi Y. The effects of organizational and ethical climates on misconduct at work. J Bus Ethics. 2001;29(4):325-337. doi:10.1023/A:1010710022834

47. Cameron Montgomery D, Blodgett JG, Barnes JH. A model of financial securities salespersons' job stress. J Serv Mark. 1996;10 (3):21-38. doi:10.1108/08876049610119776

48. Chen J-C, Silverthorne C, Hung J-Y. Organization communication, job stress, organizational commitment, and job performance of accounting professionals in Taiwan and America. Leadersh Organ Dev J. 2006;27(4):242-249. doi:10.1108/01437730610666000

49. Fairbrother K, Warn J. Workplace Dimensions, Stress and Job Satisfaction. Journal of managerial psychology. 2003. doi:10.1108/ 02683940310459565

50. Le FM, Matheny J, Kolt GS. Eustress, distress, and interpretation in occupational stress. J Manag Psychol. 2003;18(7):726-744 doi: $10.1108 / 02683940310502412$

51. Greenberg J, Baron RA. Instructor's Manual with Transparency Masters: Behavior in Organizations Understanding and Managing the Human Side of Work. Prentice Hall; 1995.

52. Naumann E. Antecedents and consequences of satisfaction and commitment among expatriate managers. Gr Organ Manag. 1993;18(2):153-187. doi:10.1177/1059601193182003

53. Sullivan SE, Bhagat RS. Organizational stress, job satisfaction and job performance: where do we go from here? J Manage. 1992;18 (2):353-374

54. Tett RP, Meyer JP. Job satisfaction, organizational commitment, turnover intention, and turnover: path analyses based on metaanalytic findings. Pers Psychol. 1993;46(2):259-293. doi:10.1111/ j.1744-6570.1993.tb00874.x
55. Williams LJ, Hazer JT. Antecedents and consequences of satisfaction and commitment in turnover models: a reanalysis using latent variable structural equation methods. J Appl Psychol. 1986;71 (2):219. doi:10.1037/0021-9010.71.2.219

56. Milczarek M, Schneider E, González E. European agency for safety and health at work. OSH Fig Stress Work Fig Luxemb Eur Communities. 2009:112

57. Irastorza X, Milczarek M, Cockburn W Second European Survey of Enterprises on New and Emerging Risks (ESENER-2): overview report: managing safety and health at work. Publications Office of the European Union; 2016.

58. Weinberg A, Bond F, Cooper C, Sutherland VJ. Organizational Stress Management: a Strategic Approach. Palgrave Macmillan; 2010.

59. Hodliffe MC. The Development and Validation of the Employee Resilience Scale (empres): The Conceptualisation of a New Model. 2014.

60. Meichenbaum D. Important Facts about Resilience: A Consideration of Research Findings about Resilience and Implications for Assessment and Treatment. Meliss Inst Miami, FL; 2007.

61. Block J, Kremen AM. IQ and ego-resiliency: conceptual and empirical connections and separateness. J Pers Soc Psychol. 1996;70(2):349. doi:10.1037/0022-3514.70.2.349

62. Luthans $F$. The need for and meaning of positive organizational behavior. J Organ Behav. 2002;695-706. doi:10.1002/job.165

63. Ungar M. The social ecology of resilience: addressing contextual and cultural ambiguity of a nascent construct. Am J Orthopsychiatry. 2011;81(1):1. doi:10.1111/j.1939-0025.2010.01067.x

64. Karoly P. Mechanisms of self-regulation: a systems view. Annu Rev Psychol. 1993;44(1):23-52. doi:10.1146/annurev.ps.44.020193.000323

65. Buckner JC, Mezzacappa E, Beardslee WR. Characteristics of resilient youths living in poverty : the role of self-regulatory processes. Dev Psychopathol. 2003;15:139-162.

66. Gardner TW, Dishion TJ, Connell AM. Adolescent self-regulation as resilience: resistance to antisocial behavior within the deviant peer context. J Abnorm Child Psychol. 2008:273-284. doi:10.1007/ s10802-007-9176-6

67. Blau P. Power and exchange in social life. New York J Wiley Sons. 1964;352.

68. Kacmar KM, Carlson DS. Further validation of the perceptions of politics scale (POPS): a multiple sample investigation. J Manage. 1997;23(5):627-658.

69. Blau G, Andersson L. Testing a measure of instigated workplace incivility. J Occup Organ Psychol. 2005;78(4):595-614. doi:10.1348/ $096317905 \mathrm{X} 26822$

70. Cropanzano R, Mitchell MS. Social exchange theory: an interdisciplinary review. J Manage. 2005;31(6):874-900.

71. Bakker AB, Demerouti E. The job demands-resources model: state of the art. J Manag Psychol. 2007;22(3):309-328. doi:10.1108/ 02683940710733115

72. Schaufeli WB, Bakker AB. Job demands, job resources, and their relationship with burnout and engagement: a multi-sample study. $J$ Organ Behav. 2004;25(3):293-315. doi:10.1002/job.248

73. Weiss HM, Cropanzano R. Affective Events Theory: A Theoretical Discussion of the Structure, Causes and Consequences of Affective Experiences at Work. 1996. In: Staw BM, Cummings LL, editors. Research in organizational behavior. Greenwich, CT: JAI Press. Res Organ Behav An Annu Ser Anal essays Crit Rev içinde (1-74) Greenwich, CT JAI. 1996

74. Lim S, Cortina LM, Magley VJ. Personal and workgroup incivility: impact on work and health outcomes. J Appl Psychol. 2008;93 (1):95. doi:10.1037/0021-9010.93.1.95

75. Leiter MP. Coping patterns as predictors of burnout: the function of control and escapist coping patterns. J Organ Behav. 1991;12 (2):123-144. doi:10.1002/job.4030120205 
76. Leymann H, Gustafsson A. Mobbing at work and the development of post-traumatic stress disorders. Eur J Work Organ Psychol. 1996;5(2):251-275. doi:10.1080/13594329608414858

77. Lazarus RS, Folkman S. Stress, Coping and Appraisal. Springer publishing company. 1984.

78. Monat A, Lazarus RS. Stress and Coping: An Anthology. Columbia University Press; 1991.

79. Meisler G, Vigoda-Gadot E, Drory A. Stress, psychological strain, and reduced organizational effectiveness: the destructive consequences of the use of intimidation and pressure by supervisors. In: Rosen CC, Perrewé PL, editors. Power, Politics, and Political Skill in Job Stress. Emerald Publishing Limited; 2017:51-80.

80. Parker CP, Dipboye RL, Jackson SL. Perceptions of organizational politics: an investigation of antecedents and consequences. $J$ Manage. 1995;21(5):891-912.

81. Saleem H. The impact of leadership styles on job satisfaction and mediating role of perceived organizational politics. Procedia-Social Behav Sci. 2015;172:563-569. doi:10.1016/j. sbspro.2015.01.403

82. Rosen CC, Levy PE. Stresses, swaps, and skill: an investigation of the psychological dynamics that relate work politics to employee performance. Hum Perform. 2013;26(1):44-65. doi:10.1080/ 08959285.2012.736901

83. Kacmar KM, Ferris GR. Perceptions of organizational politics scale (POPS): development and construct validation. Educ Psychol Meas. 1991;51(1):193-205. doi:10.1177/0013164491511019

84. Abbas M, Raja U, Darr W, Bouckenooghe D. Combined effects of perceived politics and psychological capital on job satisfaction, turnover intentions, and performance. $J$ Manage. 2014;40 (7): 1813-1830.

85. Miller BK, Rutherford MA, Kolodinsky RW. Perceptions of organizational politics: a meta-analysis of outcomes. J Bus Psychol. 2008;22(3):209-222. doi:10.1007/s10869-008-9061-5

86. Chang C-H, Rosen CC, Levy PE. The relationship between perceptions of organizational politics and employee attitudes, strain, and behavior: a meta-analytic examination. Acad Manag J. 2009;52 (4):779-801. doi:10.5465/amj.2009.43670894

87. Hendrix WH, Ovalle NK, Troxler RG. Behavioral and physiological consequences of stress and its antecedent factors. $J$ Appl Psychol. 1985;70(1):188. doi:10.1037/0021-9010.70.1.188

88. Colligan TW, Higgins EM. Workplace stress: etiology and consequences. J Workplace Behav Health. 2006;21(2):89-97. doi:10.1300/J490v21n02_07

89. Salem I, Kattara H. Transformational leadership : relationship to job stress and job burnout in five-star hotels. Tour Hosp Res. 2015. doi:10.1177/1467358415581445

90. Michie S. Causes and management of stress at work. Occup Environ Med. 2002;59(1):67-72. doi:10.1136/oem.59.1.67

91. O'neill JW, Davis K. Work stress and well-being in the hotel industry. Int J Hosp Manag. 2011;30(2):385-390. doi:10.1016/j. ijhm.2010.07.007

92. Jamal M. Relationship of job stress and Type-A behavior to employees' job satisfaction, organizational commitment, psychosomatic health problems, and turnover motivation. Hum Relations. 1990;43(8):727-738. doi:10.1177/001872679004300802

93. Mursali A, Basuki E, Dharmono S. Relationship between noise and job stress at a private thread spinning company. Universa Med. 2016;28(1):8-16.

94. Cicei CC. Occupational stress and organizational commitment in Romanian public organizations. Procedia-Social Behav Sci. 2012;33:1077-1081. doi:10.1016/j.sbspro.2012.01.288

95. Hobfoll SE. Social and psychological resources and adaptation. Rev Gen Psychol. 2002;6(4):307. doi:10.1037/1089-2680.6.4.307

96. Hirschi T. Self-control and Crime. In: Baumeister RF, Vohs KD, editors, Handbookof Self-Regulation: Research, Theory, and Application. New York: Guilford Press. 2004.
97. Bakker AB, Demerouti E, Verbeke W. Using the job demandsresources model to predict burnout and performance. Hum Resour Manage. 2004;43(1):83-104. doi:10.1002/hrm.20004

98. Bryman A, Bell E. Business Research Methods. USA: Oxford University Press; 2015.

99. LasisiOlukayode J, Okuneye MY, Shodiya AO. Antecedents of counter work behavior in public sector organizations: evidence from nigeria. Kuwait Chapter Arab J Bus Manag Rev. 2014;3(9):58.

100. Saunders MNK, Lewis P. Doing Research in Business \& Management: An Essential Guide to Planning Your Project. Pearson; 2012.

101. R V K, Morgan DW. Determining sample size for research activities. Educ Psychol Meas. 1970;30(3):607-610. doi:10.1177/ 001316447003000308

102. Hair JF, Sarstedt M, Ringle CM, Mena JA. An assessment of the use of partial least squares structural equation modeling in marketing research. J Acad Mark Sci. 2012;40(3):414-433. doi:10.1007/ s11747-011-0261-6

103. Sams D An empirical examination of job stress and management of emotionally-based behavior: frontline social service personnel perspective. Grad Theses Diss; June 2005. Available from: https:// scholarcommons.usf.edu/etd/842. Accessed September 18, 2018.

104. Stephens JP, Heaphy ED, Carmeli A, Spreitzer GM, Dutton JE. Relationship quality and virtuousness: emotional carrying capacity as a source of individual and team resilience. J Appl Behav Sci. 2013;49(1):13-41. doi:10.1177/0021886312471193

105. Ng TWH, Feldman DC. Age and innovation-related behavior: the joint moderating effects of supervisor undermining and proactive personality. J Organ Behav. 2013;34(5):583-606. doi:10.1002/ job. 1802

106. Malhotra NK, Kim SS, Patil A. Common method variance in IS research: a comparison of alternative approaches and a reanalysis of past research. Manage Sci. 2006;52(12):1865-1883. doi:10.1287/ mnsc. 1060.0597

107. Papa A, Dezi L, Gregori GL, Mueller J, Miglietta N. Improving innovation performance through knowledge acquisition: the moderating role of employee retention and human resource management practices. J Knowl Manag. 2018. doi:10.1108/JKM-09-2017-0391

108. Chang S-J, Van Witteloostuijn A, Eden L. From the Editors: Common Method Variance in International Business Research. $J$ Int Bus Stud. 2010. doi:10.1057/jibs.2009.88

109. Hair JF Jr, Sarstedt M, Hopkins L, G. Kuppelwieser V. Partial least squares structural equation modeling (PLS-SEM) an emerging tool in business research. Eur Bus Rev. 2014;26(2):106-121. doi:10.1108/EBR-10-2013-0128

110. Hair JF, Ringle CM, Sarstedt M. PLS-SEM: indeed a silver bullet. $J$ Mark Theory Pract. 2011;19(2):139-152. doi:10.2753/MTP10696679190202

111. Ringle CM, Wende S, Becker J-M SmartPLS 3. Boenningstedt SmartPLS GmbH; 2015. Available from: http://www.smartpls.com.

112. Hair JF Jr, Hult GTM, Ringle C, Sarstedt M. A Primer on Partial Least Squares Structural Equation Modeling (PLS-SEM). Sage Publications; 2016.

113. Bacon DR, Sauer PL, Young M. Composite reliability in structural equations modeling. Educ Psychol Meas. 1995;55(3):394-406. doi:10.1177/0013164495055003003

114. Chin WW. How to write up and report PLS analyses. In: Vinzi VE, Chin WW, Henseler J, Wang H, editors. Handbook of Partial Least Squares. Springer; 2010:655-690. Berlin, Heidelberg.

115. Mela CF, Kopalle PK. The impact of collinearity on regression analysis: the asymmetric effect of negative and positive correlations. Appl Econ. 2002;34(6):667-677. doi:10.1080/00036840110058482

116. Hulland J. Use of partial least squares (PLS) in strategic management research: a review of four recent studies. Strateg Manag J. 1999;20(2):195-204. doi:10.1002/(SICI)1097-0266 (199902)20:2<195::AID-SMJ13>3.0.CO;2-7 
117. Fornell C, Larcker DF. Structural equation models with unobservable variables and measurement error: algebra and statistics. $J$ Mark Res. 1981;382-388. doi:10.1177/002224378101800313

118. Hair JF, Ringle CM, Sarstedt M. Partial Least Squares Structural Equation Modeling: Rigorous Applications, Better Results and Higher Acceptance. Long Range Planning. 2013;46:1e12 Elsevier.

119. Lucas RE, Diener E, Suh E. Discriminant validity of well-being measures. J Pers Soc Psychol. 1996;71(3):616. doi:10.1037/00223514.71.3.616

120. Henseler J, Ringle CM, Sarstedt M. A new criterion for assessing discriminant validity in variance-based structural equation modeling. J Acad Mark Sci. 2015;43(1):115-135. doi:10.1007/s11747014-0403-8

121. Cohen J. A power primer. Psychol Bull. 1992;112(1):155. doi:10.1037/0033-2909.112.1.155

122. Stone M. Cross-validatory choice and assessment of statistical predictions. J R Stat Soc Ser B. 1974;36(2):111-147.

123. Geisser S. The predictive sample reuse method with applications. J Am Stat Assoc. 1975;70(350):320-328. doi:10.1080/01621459. 1975.10479865

124. Vigoda-Gadot E, Talmud I. Organizational politics and job outcomes: the moderating effect of trust and social support. J Appl Soc Psychol. 2010;40(11):2829-2861. doi:10.1111/j.1559-1816.2010.00683.x

125. Vitaro F, Gendreau PL, Tremblay RE, Oligny P. Reactive and proactive aggression differentially predict later conduct problems. J Child Psychol Psychiatry Allied Discip. 1998;39(3):377-385. doi:10.1017/S0021963097002102

126. Mack DA, Shannon C, Quick JD, Campbell Quick J. Stress and the preventative management of workplace violence. Monogr Organ Behav Ind Relations. 1998;23:119-142.

127. Martinko MJ, Gundlach MJ, Douglas SC. Toward an integrative theory of counterproductive workplace behavior: a causal reasoning perspective. Int J Sel Assess. 2002;10(1-2):36-50. doi:10.1111/ 1468-2389.00192
128. Preacher KJ, Hayes AF. Asymptotic and resampling strategies for assessing and comparing indirect effects in multiple mediator models. Behav Res Methods. 2008;40(3):879-891.

129. Mertens W, Recker J, Kummer T-F, Kohlborn T, Viaene S. Constructive deviance as a driver for performance in retail. J Retail Consum Serv. 2016;30:193-203. doi:10.1016/j.jretconser.2016.01.021

130. Michel JS, Newness K, Duniewicz K. How Abusive Supervision Affects Workplace Deviance: A Moderated-Mediation Examination of Aggressiveness and Work-Related Negative Affect. $J$ Bus Psychol 2015. doi:10.1007/s10869-015-9400-2

131. Hofstede G. Culture's Consequences: Comparing Values, Behaviors, Institutions and Organizations across Nations. Sage publications; 2001.

132. Heffernan M, Dundon $\mathrm{T}$ Researching employee reactions to high performance work systems in the service sector: the role of organisational justice theory. In: 16th ILERA (IIRA) World Congress; Philadelphia, USA, 2-5 July 2012. doi:10.1094/PDIS-11-11-0999PDN

133. Hair JF, Black WC, Babin BJ, Anderson RE, Tatham RL. Multivariate data analysis (Vol. 2006;6). Upper Saddle River (NJ):Pearson Prentice Hall; 2006

134. Giorgi G, Arcangeli G, Mucci N, Cupelli V. Economic stress in the workplace: the impact of fear of the crisis on mental health. Work. 2015;51(1):135-142. doi:10.3233/WOR-141844

135. Fuller JB, Marler L, Hester K, Frey L, Relyea C. Construed external image and organizational identification: a test of the moderating influence of need for self-esteem. J Soc Psychol. 2006;146 (6):701-716. doi:10.3200/SOCP.146.6.701-716

136. Jetten J, Hornsey MJ. Deviance and dissent in groups. Annu Rev Psychol. 2014;65:461-485. doi:10.1146/annurev-psych-010213115151

137. O’Connor PJ, Stone S, Walker BR, Jackson CJ. Deviant behavior in constrained environments: sensation-Seeking predicts workplace deviance in shallow learners. Pers Individ Dif. 2017;108:20-25. doi:10.1016/j.paid.2016.11.062
Psychology Research and Behavior Management

\section{Publish your work in this journal}

Psychology Research and Behavior Management is an international, peer-reviewed, open access journal focusing on the science of psychology and its application in behavior management to develop improved outcomes in the clinical, educational, sports and business arenas. Specific topics covered in the journal include: Neuroscience, memory and decision making; Behavior modification and management; Clinica applications; Business and sports performance management; Social and developmental studies; Animal studies. The manuscript management system is completely online and includes a very quick and fair peer-review system, which is all easy to use. Visit http://www. dovepress.com/testimonials.php to read real quotes from published authors. 